\title{
Digital humanities and the elusive "thing"
}

\section{Torsten Arni Caleb Andreasen}

MedieKultur 2014, 57, 75-93

Published by SMID | Society of Media researchers In Denmark | www.smid.dk The online version of this text can be found open access at www.mediekultur.dk

The present article examines the current academic encounter with the "thing" of the digital humanities, i.e., with the digital as both a source of crisis and an attempt to control this crisis. By mapping conceptualisations of the digital as an object of study, a tool and the constitution of new practices, the "thing" is presented from the threefold perspective of access, evidence and control: access as the newfound availability and emancipation of the digital object, evidence as the cognitive approach marshalled in response to the surge of data, and control as the new ruling practice, whether academic, ethical or critical. The article seeks to demonstrate that the "thing" cannot be immediately grasped or pinned down, that whenever you think you have it, it turns out to be somewhere else. The proposed threefold perspective of access, evidence, and control is but a way of closing in on something that remains forever elusive.

What one finds in das Ding is the true secret.

(Lacan, 1997, p. 46)

No, digital humanities is nothing new. Let us dutifully mention the name Busa and be done with it. It might have been called something else, it might have been performed on a smaller scale and in simpler ways, but the digital has long since penetrated the perennially thick walls of the ivory tower. Something is new, though, isn't it? In the quintessential academic acts of reading and writing, the hand once wrote and the eye read. Then, the machine took 
over the feeding of the reading mind. At some point, in the midst of battle, a machine COLOSSUS read the writing of a machine ENIGMA. Now, the machine not only reads the machine, it reads the reader and writes of its own accord. When the computer reads, it writes elsewhere; but now, in addition, when the eye reads the computer, the computer reads and rewrites the eye and feeds it back into the writing process. The colossal ubiquity of read/write operations almost seems to intimate that enigma is no more.

Speaking of the word processor, Derrida once said: “I'm always wondering what would have happened to Plato, Descartes, Hegel, Nietzsche, and even to Heidegger [...], if they had encountered this 'thing', not only as an available tool but also as a subject for reflection. [...] $[\mathrm{H}]$ ow would they have interpreted a culture with the tendency to be dominated [...] by these types of technological devices for writing and archiving?" (Derrida, 2005, pp. 30-31).

Taking Paul Valéry, Walter Benjamin and Martin Heidegger as points of departure, the present article wonders about the current academic encounter with "this 'thing'" as an object of study, as a tool and the constitution of new practices. The "thing" is presented from the threefold perspective of access, evidence and control: access as the newfound availability and emancipation of the digital object, evidence as the cognitive approach marshalled in response to the surge of data and control as the new ruling practice, whether academic, ethical or critical.

Access, evidence and control allow us not to grasp but to close in on the "thing", which seems to have forced us to redefine so many - once steady - pillars of academia: the humanities (digital or not), the archive, the relevance of theory, etc. But if this disciplinary frenzy, this conceptual confusion, is something new, then what is its cause? What is the thing of the something? ${ }^{2}$

There is a general sentiment that it has to do with the digital: "Everyone now accepts that digital technology is changing scholarship" (Prescott, 2012). And "[n]o one can seriously doubt that the intercourse of the humanities research community will be digitally organized" (McGann, 2012). The digital is clearly having a profound impact on every single aspect of scholarship, both on an institutional, theoretical, methodological, conceptual and objective level. "That is, computational technology has become the very condition of possibility required in order to think about many of the questions raised in the humanities today" (Berry, 2012, p. 3).

If the thing is the digital, then what is the digital thing? Is it the constitutive modules of zeros and ones? Their electromagnetic inscription on spinning platters or solid state drives? Their operationalization via code instructions? Or is it, rather, the executed code as runtime experience and interface? Is the digital best perceived as a cloud-like network of software nodes or the universal archive as the ready availability of all digital objects?

The present article proposes a mapping of the on-going frenzy and confusion from the calm conceptual collection of access, evidence and control. ${ }^{3}$ They each represent a response to the elusiveness of the digital "thing". Access has hopes and fears for the digital object and mostly wants it to stay in its place. Evidence tries to study it and gain from it 
all the knowledge that was so frustratingly unattainable in its arcane analogue ancestors. Control seeks to establish new practices that let us harvest from its digital soil academic mastery, personal edification and communal benefit.

\title{
Closing in on the thing
}

Let us begin with a pre-digital encounter with the "thing". In 1928, Paul Valéry expressed amazement regarding the impact of technological development:

\begin{abstract}
Works of art will acquire a kind of ubiquity. We shall only have to summon them and there they will be, either in their living actuality or restored from the past. They will not merely exist in themselves but will exist wherever someone with a certain apparatus happens to be. A work of art will cease to be anything more than a kind of source or point of origin whose benefits will be available and - quite fully so - wherever we wish (Valéry, 1964, pp. 225-6).
\end{abstract}

The object will be ubiquitous, it will be available - and "fully so" - for pure access. It is difficult to read the following and not think of contemporary streaming services: "it will be wonderfully pleasant to be able to transform at will an empty hour, an interminable evening, an endless Sunday, into an enchantment, an expression of tenderness, a flight of the spirit" (Valéry, 1964, p. 228).

Whatever your taste or poison - Beethoven or Beyoncé, Brötzmann or Bacharach Spotify, Wimp, Deezer and its siblings now give any given Sunday its musical fill just as the Berliner Philharmoniker happily notifies your gadget of choice whenever its audience is settling into their seats so that you may privately do the same and virtually join their number. Valéry noted that, at the time, visual phenomena had yet to be mastered in the same way as the audible; but, as demonstrated by services as diverse as Netflix and the Google Art Project, he rightfully predicted: "That will happen some day" (Valéry, 1964, p. 228).

Walter Benjamin quoted Valéry at length in the beginning of "The Work of Art in the Age of Mechanical Reproduction."4 The quoted passage, which claims that "[f]or the last twenty years neither matter nor space nor time has been what it was from time immemorial"'s (Valéry quoted in Benjamin, 1968, 217), simply hovers uncommented en exergue before the preface. Something has happened as described by Valéry, and Benjamin sets out to trace its consequences with regard to the authenticity of the work of art: Mechanical reproduction depreciates the presence of the object, its aura, because it severs the object's ties to its history or tradition. ${ }^{6}$ Benjamin, of course, saw this as a political potential and focused on film's influence on individual apperception, private property and mass mobilisation.

Martin Heidegger, on the other hand, was less impressed by the ability of the then new media to bring near that which is far. While Valéry focused on music and Benjamin on film, Heidegger's essay on The Thing saw the epitome of these technological developments in television: "The peak of this abolition of every possibility of remoteness is reached by tele- 
vision, which will soon pervade and dominate the whole machinery of communication" (Heidegger, 1971, p. 161). He saw a catastrophe where the technological ability to bring near creates a "uniformity in which everything is neither far nor near", a "merging of everything into the distanceless." Heidegger thus insists: "the frantic abolition of all distances brings no nearness; for nearness does not consist in shortness of distance" (Heidegger, 1971, p. 164).

Thus, we have three readings of technological access to that which was once far away: Valéry's pleasure in mediated spiritual pursuits; Benjamin's recruitment of media's destruction of aura in the service of emancipatory politics; and, finally, Heidegger's insistence that modern media cost us our understanding of actual nearness?

These are all three aspects of our technologically renewed relation to the Thing. Heidegger explicitly tried to rethink das Ding with regards to nearness in the new technological era and ended up with his famous fourfold: "Earth and sky, divinities and mortals" (Heidegger, 1971, p. 177). This fourfold is gathered in the thing: "The thing stays-gathers and unites-the fourfold. The thing things world" (Heidegger, 1971, p. 178). Unlike an object (Gegenstand), Heidegger's fourfold thing gathers and assembles the high and the low, the eternal and the mortal, the abstract and the material in a specific way. Only by thinking this gathering, this assemblage, are we able to think the thing and its relation to the world as something that concerns and conditions us instead of merely as a resource to be stored and exploited. ${ }^{8}$

Let us try, then, to consider the thing that seems to be happening within or around the digital humanities. Thinking the thing instead of the object should, hopefully, allow us to circumvent the deluge of questions presented at the beginning of this article - is it this or is it that? - as well as the often comical attempts to patent the best possible terminology or disciplinary approach. Our goal here is to close in on the "thing" via the threefold perspective of access, evidence and control as the specific gathering that both conditions and haunts contemporary humanities.

\section{Access}

In a certain way, Valéry, Benjamin and Heidegger all took transmission, access to something via the transmissions of sound and image, as their point of departure. New modes of transmission influenced the spiritual formation of the self, property relations and the mobilisation of the masses and, finally, our cognitive relation to the world. In our day, this access via transmission is, of course, epitomised by the distributed digital network: "Inside the dense web of distributed networks, it would appear that everything is everywhere" (Galloway \& Thacker, 2007, p. 4).

But is the network, then, the "thing" of the digital? Is the rise to prominence of the distributed network the central paradigm of our contemporary societies, cultures and academic trepidations? And, in that case, what is the network as thing? Is it the rhizome, a collection of protocols, or is it the swarm of the Furies? 
The network obviously plays a pivotal role in digital access as its dominant form of transmission, but it is nothing but an abstraction, a set of unemployed conventions noted in the RFCs, ${ }^{9}$ without some form of transmitted content, without that of which the network is a transmission. Kittler always insisted on the "necessary and sufficient" trinity of transmission, storage and computation. ${ }^{10}$ The sending and receiving via the network requires read/ write operations within computer memory and between memory and storage. So, what about storage, access to the digitally stored object?

Apart from transmission, storage and computation, Kittler was fond of another conceptual triplet, that of Lacan's distinction between the real, the symbolic and the imaginary, which he found expressed in the phonograph, the typewriter and the cinematograph, respectively. Thus, Kittler would to some extent agree with Valéry's description of the fullness of access to sound - not because there is no possible quality loss but simply because the sound of the real itself inscribed traces in the substratum. When Edison shouted his famous "Hullo" into the mouthpiece of what was to become the phonograph, the vibrations of his voice left an imprint which to this day allows a faint echo of that primordial bellow to resound from the past. The real ceased not to write itself, as Kittler would echo Lacan.

Benjamin's perception of cinema, on the other hand, is that of a break with our commonplace images:

Our taverns and our metropolitan streets, our offices and furnished rooms, our railroad stations and our factories appeared to have us locked up hopelessly. Then came the film and burst this prison-world asunder by the dynamite of the tenth of a second, so that now, in the midst of its far-flung ruins and debris, we calmly and adventurously go traveling (Benjamin, 1968, p. 236).

If, for Kittler, "the imaginary has the status of cinema" because of its flickering mirror edition of the "real" world (Kittler, 1999, 16), then, for Benjamin, this ability to produce a new imaginary and new ways of consuming image worlds is the key to the future. If, as Althusser would have it, ideology is the imaginary relation of individuals to their real conditions of existence, then Benjamin's cinema is in its very technological form the foundation of a new critique of ideology. ${ }^{11}$

Finally, Heidegger's sense of technologically induced loss extended to the typewriter, whose machine writing reduced the word to a means of transmission and effaced the individual character of expression in favour of mechanic standardisation. ${ }^{12}$ Kittler similarly noted the digital as a renewed monopoly of the symbolic and, although Heidegger never experienced the contemporary pervasiveness of the digital, his response to digital inscription can be gathered from his clear statement that philosophy has met its end in the new unification of the sciences in the informational manoeuvres of cybernetics. ${ }^{13}$ 


\section{Bits and archives}

What we are getting at is access to the stored object as inscription on a substrate. The voice itself held the pen when its vibrations were etched into Edison's receiving cylinder, and photographed faces impressed themselves on the camera lens with a painful light. ${ }^{14}$ Sound and image on the computer, however, are literally reduced to the symbolic writing of the computerised typewriter; and, thus, much more than the sciences has fallen under the aegis of cybernetics.

Digital inscription does not, of course, consist in the actual writing of " $1 \mathrm{~s}$ " or " $0 s^{\text {"; }}$, neither is it a simple binary of electrically charged or uncharged locations: "the magnetic patterns on the surface of the disk are not a direct representation of bit values but an abstraction of those values, filtered through a range of encoding schemes [...]" (Kirschenbaum, 2008, p. 90). In addition to the voltage flux reversals indicating the given value ( 1 or 0 ), the disc requires inscribed flux reversals to indicate location. Deciphering a hard drive through a magnetic force microscope is, thus, akin to deciphering Morse code without ever having learned the representational system: "What we see here are not simply bits, but patterns of magnetic flux reversals, a number of which may be necessary to constitute a single bit [...]. Thus while bits are the smallest symbolic units of computation, they are not the smallest inscribed unit [...]" (Kirschenbaum, 2008, p. 61). Without knowing the encoding scheme, deciphering and, thus, grasping the sense of flux reversals become more than a bit of a challenge.

Digital inscription is meaningless without the law that governs the semiotic function of flux reversals on the substrate as well as the retrievability of their semantic content; and we could, therefore, argue that digital inscription is always already an archive. This is a proposition that is bound to annoy the pundit who detects a current lamentable "conflation of libraries, museums, and archives" and bemoans an "inflation of the term 'archive' [...]" (Manoff, 2004, p. 10)..$^{15}$ Granted, the term is wearing thin and should not be used lightly; but, as mentioned at the beginning of this article - and noted from Derrida to Ernst - the archive is different after the advent of the digital. ${ }^{16}$

As already noted by Valéry, the immediacy caused by the time of transmission approaching zero also applies to the time of memory: Works of art can supposedly be restored from the past with no hint of the ghostly horrors that so often haunt such summons. According to Wendy Hui Kyong Chun, this summonable availability of the past is often perceived to assure the future:

The major characteristic of digital media is memory. [...] Memory allegedly makes digital media an ever-increasing archive in which no piece of data is lost. This always-thereness of new media is also what links it to the future as future simple, as what will be, as predictable progress. By saving the past, it was supposed to make knowing the future easier (Chun, 2008, p. 154). 
But the "archival promise" of the complete mnemonic accumulation of the past and the subsequent cybernetic calculation of the future on the basis of this completed data set is an illusion. Digital memory fades. As Chun argues, digital memory is an enduring ephemeral depending on persistent rewriting; and, thus far, even non-volatile memory has limited read-write capacity. ${ }^{17}$

From cathode ray tubes to DRAM and RAIDs containing multiple hard drives ever in danger of spinning out of control and into a twirling encounter with the all-too-tactile inscriptions of the real, digital memory is not the assured storage once hoped for. The RAID (Redundant Array of Inexpensive/Independent Disks) is an example of large-scale storage based not on the assumption but on the sure knowledge that participating disks will fail.

Instantaneous access to ephemeral digital inscriptions on networked substrates makes the digital archive a question of time: "Thus, the so-called Internet 'archive' becomes radically temporalized. It is rather hypertemporal than hyperspatial, based on the aesthetic of immediate feedback, recycling and refreshing rather than on the ideal of locked-away storage for eternity" (Ernst, 2010, p. 68). Storage itself then becomes a mode of transmission with data constantly being moved around or rewritten. Access is no longer the simple transmission of an object from one location to another. The object itself is a spectral inscription constantly rewritten in a black box that, when opened, reveals nothing legible to the naked eye. And even the right optics reveal only flux reversals indecipherable without knowledge of the encoding scheme. Any act of reading is an act of deciphering, i.e., "[o]bjects exist only upon use" (Galloway, 2004, p. 74).

\section{Code}

Digital inscription in transmission, this constant flux of networked read/write operations, ${ }^{18}$ is, then, finally, nothing without the computational operationalization of the very same inscriptions. From the encoding scheme to the interface of web applications, the digital operates by code. But, here again, we run into the same problem: What is the code thing? Is it the programmer's source code, compiled machine code, electromagnetic disk inscriptions or possibly the execution of code?

Just as digital inscription requires an encoding scheme in order to make sense, "the complete syntactic and semantic rules of a computer language must be defined and written into any environment designed to interpret, parse, or execute it" (Galloway, 2006, p. 322). Hence, software only works via what Galloway calls its own "meta-medial reflection", which determines the conditions for its execution and, thus, its existence. We see higherlevel expressions of these "meta-medial" environments whenever we need to update Flash, Java or Silverlight on our computers. Valéry's streaming services have a tendency to rely on these. Netflix, for example, requires Silverlight to stream content, and streaming the concerts of the Berliner Philharmoniker requires Flash. 
But we only ever notice these interpreting layers when they stop working or they themselves announce that it is time for an update. The surface tends to eclipse what goes on in the machine room. Galloway calls this the occult logic of software: "software hides itself at exactly the moment when it expresses itself most fully" (Galloway, 2010, p. 292). Or "what you see is not what you get" (Galloway, 2012, p. 69). When gazing at the interface, its surfaces and functions are created and recreated elsewhere. When reading the source code, its ultimate expression, its telos, is an execution waiting to happen. Source code is always, in a certain way, on death row.

Chun, on the other hand, would argue that it only becomes source code after the execution: "source code only becomes a source after the fact. [...] Source code is more accurately a re-source, rather than a source. [...] Source code becomes a source only through its destruction, through its simultaneous nonpresence and presence (Chun, 2011, pp. 24-25). The readable source is nothing without its destruction in execution. Chun's argument is based on a Derridean perception of writing as spectral. The appearance of the ghost is always a re-appearance, software is always already undead..$^{19}$

It is, of course, possible to claim some form of primacy, to hierarchize the "layers" of code. The two extreme positions in this regard are Kittler's famous statement that " $[t]$ here is no software" (Kittler, 1995) and Manovich's recent reply that "[t]here is only software" (Manovich, 2013, p. 147). For Kittler, it all comes down to operations in the substrate in the form of voltages and logic gates, a position unsurprising for a man who chose the RAM/ ROM distinction over Mnemosyne as a conceptual instrument for describing "the historical evolution of the organization of memory" (Kittler, 2002, p. 406).

Manovich, on the other hand, takes issue with our initial assumption that the "thing" of the digital humanities has something to do with the digital: "None of the new media authoring and editing techniques we associate with computers are simply a result of media 'being digital.' The new ways of media access, distribution, analysis, generation, and manipulation all come from software" (Manovich, 2013, p. 148). For Manovich, software is the thing. As was already apparent in The Language of New Media (Manovich, 2001), Manovich is interested in what happens after the execution of code, its resurrection in "the techniques, the tools, and the conventions" of the runtime experience or interface.

Both Galloway and Chun explicitly try to negotiate the many aspects of code without reducing them to one primary layer. Spectral or occult, the operationalization of digital inscription in computation is as difficult to pin down as networked transmission and storage were. Deploying our folded notion of the "thing", we can push the meta-medial reflexivity of code awaiting execution as well as its undead mirror image a bit further and consider the different aspects of source, assembly and binary executable as different reflections of each other that engage in a vivid mirror dance en abyme. The different specular images are not equivalent, nor are they reducible to one another. Whether code awaits execution in the electrical circuits of the CPU or only ever awaits execution once the undead walks again 
matters less. What matters is the dance that reveals its participants in a new light and in new formations as the beat goes on.

\title{
Evidence
}

The digital thing remains elusive. Whether as transmission, inscription or computation, access is nothing but a dance of shadows. And, yet, access is claimed to cast new light and deliver a new form of clarity: evidence. Former editor-in-chief of WIRED and current drone manufacturer, Chris Anderson, even went so far as to claim the death of theory as access to enormous amounts of data will allow it to speak for itself, the archival promise of "big data":

\begin{abstract}
The new availability of huge amounts of data, along with the statistical tools to crunch these numbers, offers a whole new way of understanding the world. Correlation supersedes causation, and science can advance even without coherent models, unified theories, or really any mechanistic explanation at all. [...] It's time to ask: What can science learn from Google (Anderson, 2008).
\end{abstract}

Access to unfathomable data stores, new computational tools and the networked transmission of the cloud supposedly open a whole new world in which, with "enough data, the numbers speak for themselves." Although Chris Anderson's comments have a certain evocative power, they provide little demonstrative value. But they are interesting because of the hopes they express and the impact they had.

Matthew L. Jockers, a frequent collaborator of Franco Moretti, opens his book Macroanalysis (2013) with a reference to Chris Anderson's proposition. Surprisingly, Jockers takes its title, "Data Deluge Makes the Scientific Method Obsolete", less as a problematic and contestable provocation than as a given, now finally manifest within the humanities: "Now slowly and surely, the same elements that have had such an impact on the sciences are revolutionizing the way that research in the humanities gets done" (Jockers, 2013, p. 3).

Interestingly, this digital revolution hinges on two terms, access and evidence: "massive digital corpora offer us unprecedented access to the literary record and invite, even demand, a new type of evidence gathering and meaning making" (Jockers, 2013, p. 8, my emphasis). The revolution is even an automatic result of access to "both large and easily accessible" data stores: "We have built it, and they are coming" (Jockers, 2013, p. 12).

Data is not evidence in itself; it becomes evidence when gathered. Access to data permits evidence gathering, which then again enables "accessing details that are otherwise unavailable, forgotten, ignored, or impossible to extract"; it allows "the computer to help us see even more, even deeper [...]" (Jockers, 2013, p. 27). Access enables evidence, which then again enables cognitive access, ultimately expressed by the metaphor of sight.

The digital is clearly not just the bringer of new evidence but also new ways for data to give evidence. But what is the new Thing of evidence? What is the evidential difference between data and metadata? Jockers begins with metadata as a "wealth of information", 
but it seems, nevertheless, to be the next best thing: "In the absence of full text, this bibliographic metadata can reveal useful information about literary trends" (Jockers, 2013, pp. 35-36). In this context, one might consider bibliographic metadata to be the data about the data of the text. But metadata constantly slips back into the role of "data" in references to metadata as "bibliographical data" (Jockers, 2013, p. 54), "title data" (Jockers, 2013, p. 55) and, from the end of the chapter on metadata: "The data discussed in this chapter [...]" (Jockers, 2013, p. 64).

Bibliographical metadata is "meta-" with regards to "full text" data but becomes data in its own right when serving as the object of study. Yet again, we notice the shadowy mirror dance in which different aspects of the digital thing switch places and reveal different sides of themselves. But the whole point of evidence is that data reveals something new, that, "[g]iven enough digital records and enough computing power, a new vantage point on human culture becomes possible" (Aiden \& Michel, 2013, p. 12). As the subtitle of Aiden and Michel's book indicates, "big data" itself functions as a lens on human culture.

What, then, is the object of this lens? How does the evidential dance of access, data and metadata cast light on the cultural phenomenon? In a recent article, Franco Moretti refers to Alexandre Koyré's distinction between a utensil and an instrument, the utensil being a sensory amplification of our common sense appraisal of the world and the instrument a "materialisation of thought ... the conscious realisation of theory", which allows us to "reach what does not fall under the domain of our senses [...]." Moretti claims that, within literary analysis, "the protagonist" is a utensil, while "character-space" as the measure of narrative space allotted to a single character, is an instrument. According to Koyré, both Galileo's telescope and microscope are such instruments.

Big data is the lens through which the computer helps us see, and something like "character-space" could, then, be likened to the adequate direction and focalisation of the gaze, a direction and focalisation based on theoretical lines of questioning. Chris Anderson expressed the desire for the "thing" to reveal itself, but the scholars faced with its ghostly formations recognise that there is more to it than that. Computation does not allow immediate access to the thing-in-itself, thus obliterating theory. The thing, rather, "has theoretical consequences" (Moretti, 2013, p. 114).

For Moretti, these consequences are best expressed in the notion "operationalizing", conceived as a "bridge from concepts to measurement, and then to the world. In our case: from the concepts of literary theory, through some form of quantification, to literary texts" (Moretti, 2013, p. 104). Character-space is, thus, an instrument, the "operationalizing" of which produces new categories. It casts, for instance, the "protagonist" to be a "special instance of the more general category of 'centrality"' (Moretti, 2013, p. 112).

No doubt, access provides new evidence; but, presented with the character-space visualisations provided by Moretti, one is tempted to grant that it is correct yet still ask whether it is true ${ }^{21}$ Is this really what concerns us in the thing? In a tone reminiscent of our initial quotes from Heidegger, Georg Simmel once wrote of the telescope: "coming closer 
to things often only shows us how far away they still are from us [...]" (Simmel, 2011, p. 516). Evidence as cognitive access via computation of transmitted data storage brings near but, perhaps, at the cost of a certain loss.

If the digital is the reign of the symbolic, as Kittler would have it, then the digital promise of access and evidence aims, as Moretti states it, to reunite the symbolic with the empirical world or, rather, to achieve an adequate symbolic representation of the real. The problem is, though, that the real is not that which resists "being caught in the symbolic network, but the fissure within the symbolic network itself. [...] for Lacan the Real - the Thing - is not so much the inert presence that curves symbolic space (introducing gaps and inconsistencies in it), but, rather, an effect of these gaps and inconsistencies" (Žižek, 2006, pp. 72-73). This is a point that Kittler keeps missing. For Kittler, the Lacanian symbolic is always an inadequate encoding of the Lacanian real; but, for Lacan, the ever improving symbolic "encoding" of the real is exactly what reproduces the real as traumatic Thing, as unknowable abyss. Thus, digital evidence in the sense of access to data as self-evident when observed via the proper lens or instrument is a discourse of truth that eludes itself.

\section{Discipline}

Moretti delivered "operationalizing" as a process "absolutely central to the new field of computational criticism, or, as it has come to be called, of the digital humanities" (Moretti, 2013, p. 103). More than simply proclaiming its able entry into the thick of the fray that is the digital humanities, Moretti here airdrops his conceptual fighter into the absolute centre of the battle to determine its outcome.

Manovich claims a similar centrality of his own champion: "Regardless of which new dimension of contemporary existence a particular social theory of the last few decades has focused on - information society, knowledge society, or network society - all these new dimensions are enabled by software" (Manovich, 2013, p. 8). Moretti believed his contestant could ensure a bridge between concept and world via measurement in an adaequatio rei et intellectus. Manovich, on the other hand, is more interested in the thing as the sine qua non of everything else of importance these days: "Software is the invisible glue that ties it all together. [...] If we don't address software itself, we are in danger of always dealing only with its effects rather than the causes [...]" (Manovich, 2013, pp. 8-9). And, furthermore, he says, "I think of software as a layer that permeates all areas of contemporary societies. [...] our analysis cannot be complete until we consider this software layer" (Manovich, 2013, p. 15).

Maybe academia always did this, but it seems that the digital provokes a special desire to claim one's own approach or perspective as the thing that restores peace to the gap between res cogitans and res extensa, the thing that lies at the foundation of everything else or the thing singularly best equipped to handle the haunting of the new thing. 
N. Katherine Hayles was clearly in marketing mode when, in How We Think (2012), she all but trademarked the term "Comparative Media Studies" as a crucial academic approach:

\begin{abstract}
Comparative Media Studies provides a rubric within which the interests of print-based and digital humanities scholars can come together to explore synergies between print and digital media, at the same time bringing into view other versions of Comparative Media Studies, such as the transition from manuscript to print culture, that have until now been relegated to specialised subfields (Hayles, 2012, p. 7).
\end{abstract}

Note that she writes "Comparative Media Studies" in title case, thus evoking the trademark effect. Comparative Media Studies is exemplary in its capacities expressed by terminology such as "provides", "synergy", "bringing into view", "enriches" and "would have wide appeal"; and, finally, she adds: "A principal aim of this book is to excavate these layers, showing through specific case studies what Comparative Media Studies involves" (Hayles, 2012, p. 10). In other words, the book's main aim is to establish this trademarkable disciplinary entity.

In Comparative Textual Media (2013), which Hayles edited along with Jessica Pressman, the brand name is written in italics and, then, abandoned in favour of "comparative textual media" in italics and, later, in the logo form of "CTM" in order to comply with the focus of that particular book (Hayles \& Pressman, 2013, p. vii). All this, of course, is nit-picking, but it is an interesting case of disciplinary marketing, especially as "the rapidly emerging field of media archaeology" (Hayles \& Pressman, 2013, p. xi), a field that, no doubt, holds its own when it comes to market tactics, receives no comparative trademark insignia.

Historian Robert Beniger describes how developments within rationalisation, bureaucracy and information, communication and processing "served to contain the control crisis of industrial society in what can be treated as three distinct areas of economic activity: production, distribution, and consumption of goods and services" (Beniger, 1986, p. 16). Beniger argues that, just as industrialisation required theoretical developments to grasp capital, energy and material processing, the information society requires reanalysis of storage, computation, transmission, and control. ${ }^{22}$

From this perspective, we could, then, compare the numerous attempts at conceptual or disciplinary dominance to Henry P. Crowell, who invented the first fully automatic production of oatmeal. "His plant literally received raw oats at one end and shipped cartons of packaged oatmeal out of the other" (Beniger, 1986, p. 265). But the efficiency of this mode of production also drove him to invent "breakfast cereal". Since his production method produced twice the amount absorbed by the national market, he had to turn to national advertisement to create demand. And, thus, Quaker Oats was born. Similarly, the sheer efficacy of new modes of evidence demands disciplinary responses to the academic control crisis fostered by the digital thing. 


\section{Control}

The digital thing has created an academic crisis of control, inviting frantic scholarly attempts to contain it and profit from it. As I have tried to demonstrate above, the situation has fostered countless questions regarding the ontological and epistemological complexities of the digital. It would, however, be yet another case of missing the thing if we only consider the new object of study and the tools and disciplines used to describe it. Galloway argues that the likes of McLuhan, Kittler and Manovich have taken a metaphysical approach to the medium as object and, instead, proposes an ethical approach to the computer-based medium as practice, cf. (Galloway, 2012, pp. 16-24).

Galloway bases this argument on the double meaning of the word techne: one as "substrate and only substrate", another as "technique, art, habits, ethos, or lived practice" (Galloway, 2012, p. 16). One considers media as externalisations of man, hypomnesis; the other asks the more political question of "middles and interfaces", i.e., modes of mediation (Galloway, 2012, p. 16). One asks the questions of formal characteristics of layers and their primacies (e.g., voltages vs. software) as well as the historical incorporation of one medium into another (print as the content of the telegraph); the other questions the relations of command expressed and executed by the computer.

Not unlike the present article, Galloway tries to circumvent the "is it this or is it that?" questions of the digital scholarly sphere. Instead, he seeks out the injunction; he demands a theoretical discourse equal to the action and command structure of the computer. This motivates his proposed shift from thinking the "black box cypher" to thinking the "black box function"23: We should not look for the inherent qualities of the Enigma machine that will allow us to decipher all its operations. Instead of building the COLOSSUS, we should analyse and exploit ENIGMA's programmability.

Although from a manifestly different political position, Bruno Latour has engaged in a similar line of questioning by arguing for a shift of focus from "matters of fact" to "matters of concern", from Gegenstand to Ding. Latour accepts the Heideggerian distinction but claims that Heidegger "traced a dichotomy between Gegenstand and Thing that was justified by nothing except the crassest of prejudices" (Latour, 2004, p. 234). Latour references the 2003 crash of the space shuttle Columbia as the "metamorphosis of an object into a thing," a matter of fact becoming a matter of concern. But he criticises Heidegger for a poor understanding of science and technology: "he had only four folds, while the smallest shuttle, the shortest war, has millions" (Latour, 2004, p. 235).

While Galloway explicitly deals with the importance of things not working, the inoperable, as a political countering of computational operationality, ${ }^{24}$ Latour deploys a mode of technocratic control whose goal is the optimisation of the machine beyond obsolete and troublesome criticism. The problem with Latour is his view of the thing as mechanic assemblage..$^{25}$ If each element of the thing is a fold, then what is the thing but the sum of its folds, the sum of its elements? Latour's folds include "passions, controls, institutions, techniques, diplomacies, wits" (Latour, 2004, pp. 235-236), but they remain operational parts in 
the mechanic assemblage. It is "the problem of composing one body from the multitude of bodies [...]" (Latour, 2005, p. 28).

Latour retransforms the thing into an object if the inoperable pieces are merely reassembled into a working whole without recognising its haunting spectrality and, thus, its power. The technocratic control deployed is clear in Latour's use of the word "manage": "How do [things as assemblages] manage to bring in the relevant parties? How do they manage to bring in the relevant issues? What change does it make in the way people make up their mind to be attached to things?" (Latour, 2005, p. 24). The thing as an ever elusive and haunting assemblage of modes of access, evidence and control is most certainly a matter of concern, but definitely not a management of relevance or a choice of attachment.

Instead of a political future or an "always already", Latour seeks to abandon the critique of power in order to take account of the present. He wants us to "abstain as much as possible from using the notion of power" (Latour, 2005, p. 29). For Latour, "[r]evolutionary time, the great Simplificator, has been replaced by cohabitation time, the great Complicator." We are moving towards a world "where more and more elements are taken into account" (Latour, 2005, p. 30). Latour sees "contemporary means and media" (Latour, 2005, p. 28) as a way of finally taking account of everything.

For Latour, the media-induced contractions in time and space evoked by Valéry, Benjamin and Heidegger - spiritual edification, political emancipation, and cognitive danger are replaced by a different injunction: "Give me one matter of concern and I will show the whole earth and heavens that have to be gathered to hold it firmly in place" (Latour, 2004, p. 246). This is the exact problem depicted throughout the present text: The desire to hold the thing firmly in place no matter the cost.

Though much is taken, much abides; and, perhaps, it us our task to counter this desire to move earth and heaven in the attempt to hold the thing firmly in place by demonstrating that access, evidence and control engage in a seductive dance of shadows in which the thing hides in its very appearance.

\section{In closing on the thing}

This article has questioned the "thing" of the digital humanities, the cause of its current conceptual and disciplinary frenzy. The goal of the article has not been to proffer a solution, the best possible approach, or the best possible terminology. The goal has been, rather, to demonstrate that the thing cannot be immediately grasped or pinned down, that whenever you think you have it, it turns out to be somewhere else. The threefold prism of access, evidence, and control is but a way of closing in on a thing that remains forever elusive.

The network has often been presented as so central a component of our age that we supposedly live in a network society. But what is the network without the transmitted object? Without the connected nodes of storage and software? Storage is itself a ghostly 
inscription that seems to evade us even when we try to stare at it through electronic microscopes. And the archives of such inscriptions, although they held great promise as the providers of the eternal presence of everything, seem to be far more ephemeral than their predecessors. Finally, computation is a many-layered thing disappearing in a mise en abyme between source, assembly and execution.

Access is quite clearly an essential aspect of the digital. But one of the reasons for the frenzy regarding the digital is the new forms of evidence provided by such immense access. Access to data has allowed for a new data object called big data. This data is sometimes data and sometimes metadata; one sometimes becomes the other depending on the perspective, but, not unlike "the archival promise", the measurability of data has led to hopes of a pure evidence, a self-revealing of the "thing" that will free us from ever having to deal with theory or models again. Supposedly, we no longer have to model the world; the world will reveal itself to us. But does this new evidential form actually mean access to the thing in itself? Or must we recognise that the new lens on human culture only demonstrates the distance to the thing and that, instead of bringing us ever closer to the real thing, digital symbolisation, in fact, produces the thing as haunting abyss of the real?

The new forms of evidence have yet to settle in a disciplinary framework and there is much competition about providing the one, the train of thought or line of questioning that will dominate this new field and enact the instance of control in the counting and measuring of new evidence. But this instance of control goes beyond mere academic disciplines. It is also a matter of ethics, of how we relate to ourselves via the digital. It is important not to forget that control entails new agencies, ethics and politics. This is also why criticism is crucial with regards to the thing. To obliterate criticism in the name of the thing, of a technocratic analytical efficiency that prides itself on the newly-won evidential capacities for complexity and, therefore, no longer sees the need for a time of succession, for a future beyond calculation, is exactly to miss the thing. The thing is not an assemblage of its parts.

The threefold perspective of access, evidence and control attempts an ever-distant approach. It does not aspire to disciplinary acceptance or dominance, nor do the three terms claim to provide the last word; they merely intimate a way of closing in on the thing while remembering that the digital thing remains ever elusive and that to grasp it is to lose it. To close in on the thing, one needs to leave it in the open.

\section{Bibliography}

Aiden, E., \& Michel, J.-B. (2013). Uncharted: Big data as a lens on human culture. New York: Riverhead Book. Althusser, L. (1971). Lenin and philosophy and other essays. London: Monthly Review Press.

Anderson, C. (2008). The end of theory: The data deluge makes the scientific method obsolete. WIRED. Retrieved October 8, 2013, from http://www.wired.com/science/discoveries/magazine/16-07/pb_theory. 
Barthes, R. (1984). Camera lucida: Reflections on photography. London: Flamingo.

Beniger, J.R. (1986). The control revolution: Technological and economic origins of the information society.

Cambridge, Mass: Harvard University Press.

Bennett, J. (2010). Vibrant matter: A political ecology of things. Duke University Press.

Benjamin, W. (1968). The work of art in the age of mechanical reproduction. In H. Arendt (Ed.), Illuminations (pp. 217-252). New York: Schocken Books.

Benjamin, W. (2013). Das Kunstwerk im Zeitalter seiner technischen Reproduzierbarkeit. (B. Lindner, Ed.). Berlin: Suhrkamp Verlag.

Berry, D.M. (Ed.). (2012). Understanding digital humanities. Basingstoke: Palgrave Macmillan.

Carr, D. (2013, February 24). For "House of Cards," using big data to guarantee its popularity. The New York Times. Retrieved September 2, 2014, from http://www.nytimes.com/2013/02/25/business/media/forhouse-of-cards-using-big-data-to-guarantee-its-popularity.html.

Chun, W.H.K. (2008). The enduring ephemeral, or the future is a memory. Critical Inquiry, 35(1), 148-171.

Chun, W.H.K. (2011). Programmed visions, software and memory. Cambridge, Mass: MIT Press.

Derrida, J. (1995). Archive fever: A Freudian impression. Diacritics, 25(2), 9-63.

Derrida, J. (2005). Paper machine. Stanford, CA: Stanford Univ. Press.

Derrida, J. (2006). Specters of Marx: The state of debt, the work of mourning and the new International. New York: Routledge.

Ernst, W. (2006). Dis/continuities: Does the archive become metaphorical in multi-media space? In W. Hui Kyong Chun \& T. Keenan (Eds.), New media, old media: A history and theory reader (pp. 105-124). New York: Routledge.

Ernst, W. (2010). Cultural archive versus technomathematical storage. In E. Røssaak (Ed.), The archive in motion (pp. 53-73). Oslo: Novus Press.

Galloway, A R. (2004). Protocol: How control exists after decentralization. Cambridge, Mass: MIT Press.

Galloway, A.R. (2006). Language wants to be overlooked: On software and ideology. Journal of Visual Culture, 5(3), 315-331.

Galloway, A.R. (2008). The unworkable interface. New Literary History, 39(4), 931-955.

Galloway, A.R. (2010). Networks. In Critical terms for media studies (pp. 280-296). Chicago \& London: The University of Chicago Press.

Galloway, A.R. (2011). Black box, black bloc. In B. Noys (Ed.), Communization and its discontents: Contestation, critique, and contemporary struggles (pp. 237-249). New York: Automedia.

Galloway, A.R. (2012). The interface effect. Cambridge, UK: Polity Press.

Galloway, A.R., \& Thacker, E. (2007). The exploit: A theory of networks. Minneapolis: University of Minnesota Press.

Garcia, T. (2014). Form and object: A treatise on things. Edinburgh: Edinburgh University Press.

Hansen, M.B.N. (forthcoming). Feed-Forward: On the future of twenty-first-century media. Chicago ; London: University of Chicago Press.

Harman, G. (2002). Tool-being: Heidegger and the metaphysics of objects. Open Court Publishing Company. Hayles, K., \& Pressman, J. (2013). Comparative textual media: transforming the humanities in the postprint era. Minneapolis: University of Minnesota Press.

Hayles, N.K. (2012). How we think: Digital media and contemporary technogenesis. University of Chicago Press.

Heidegger, M. (1971). The Thing. In Poetry, language, thought (pp. 161-184). New York: Harper \& Row.

Heidegger, M. (1977). The question concerning technology and other essays. New York: Harper \& Row.

Heidegger, M. (1982). Parmenides. Frankfurt am Main: Vittorio Klostermann. 
Heidegger, M. (2000). Zur Frage nach der Bestimmung der Sache des Denkens (30 October 1965). In Reden und andere Zeugnisse eines Lebensweges 1910-1976 (pp. 620-633). Frankfurt am Main: Vittorio Klostermann.

Jockers, M.L. (2013). Macroanalysis: Digital methods and literary history. Urbana, IL: University of Illinois Press.

Kant, I. (1998). Kritik der reinen Vernunft. Hamburg: Felix Meiner Verlag.

Kirschenbaum, M.G. (2008). Mechanisms: New media and the forensic imagination. Cambridge, Mass: MIT Press.

Kittler, F. $(1995,10)$. There is no software. Retrieved September 2, 2014, from http://www.ctheory.net/articles.aspx?id=74.

Kittler, F. (1999). Gramophone, film, typewriter. Stanford, CA: Stanford University Press.

Kittler, F. (2002). Memories are made of you. In R. Comay (Ed.), Lost in the archives (pp. 405-416). Toronto, ON: Alphabet City Media.

Kittler, F. (2013). Martin Heidegger, Medien und die Götter Griechenlands - Ent-fernen heißt die Götter nähern. In Die Wahrheit der technischen Welt: Essays zur Genealogie der Gegenwart (pp. 377-390). Berlin: Suhrkamp.

Lacan, J. (1997). The ethics of psychoanalysis, 1959-1960. New York: Norton.

Latour, B. (2004). Why has critique run out of steam? From matters of fact to matters of concern. Critical Inquiry, 30(2), 225-248.

Latour, B. (2005). From Realpolitik to Dingpolitik or how to make things public. In P. Weibel \& B. Latour (Eds.), Making things public: Atmospheres of democracy (pp. 4-31). Cambridge, Mass.: [Karlsruhe, Germany]: MIT Press; ZKM/Center for Art and Media in Karlsruhe.

Manoff, M. (2004). Theories of the archive from across the disciplines. Portal: Libraries and the Academy, 4(1), 9-24.

Manovich, L. (2001). The language of new media. Cambridge, Mass: MIT Press.

Manovich, L. (2013). Software takes command. New York: Bloomsbury.

McGann, J. (2012, 8). Memory now. 4Humanities. Retrieved September 2, 2014, from http://4humanities. org/2012/08/jerome-j-mcgann-memory-now-2/.

McLuhan, M. (1994). Understanding media: The extensions of man. Cambridge, MA: MIT Press.

Moretti, F. (2013). “Operationalizing." New Left Review, (84), 103-119.

Morton, T. (2013). Hyperobjects, philosophy and ecology after the end of the world. University of Minnesota Press.

Olsen, B. (2010). In defense of things: Archaeology and the ontology of objects. Altamira Press.

Prescott, A. (2012, 7). Making the digital human: Anxieties, possibilities, challenges. Digital Riffs. Retrieved September 2, 2014, from http://digitalriffs.blogspot.dk/2012/07/making-digital-human-anxieties.html.

Simmel, G. (2011). The philosophy of money. London: Routledge.

Stiegler, B. (2011). The decadence of industrial democracies. Cambridge [etc.]: Polity Press.

Streitfeld, D. (2013, December 24). As new services track habits, the e-books are reading you. The New York Times. Retrieved September 2, 2014, from http://www.nytimes.com/2013/12/25/technology/as-newservices-track-habits-the-e-books-are-reading-you.html.

Valery, P. (1960). The Problem of Museums. in The Collected Works of Paul Valery, Vol. 12. New York: Pantheon Books.

Valéry, P. (1964). The Conquest of ubiquity. In Aesthetics (pp. 225-228). London: Routledge \& Kegan Paul.

Žižek, S. (2006). How to read Lacan. London: Granta. 


\section{Notes}

1 Services that charge a fee for unlimited access to e-books, movies or music now employ detailed usage data in the production or selection of their content. Netflix, thus, chose to produce the TV series House of Cards because of the platform usage data. Cf. Carr, 2013 and Streitfeld, 2013.

2 Cf. the link between the "thing" and the Latin word "causa", cf. Lacan, 1997, p. 43 and Heidegger, 1971, p. 173. Throughout the article, "the thing" is conceived in Lacanian fashion as a traumatic encounter with the real and in Heideggerian fashion as the gathering of worlds.

3 Any mapping is in its nature woefully incomplete and the present attempt is no exception. Many relevant contributions to the field have been consciously omitted, many unwillingly or simply because of ignorance. Although the ground covered is far from exhaustive, the proposed threefold approach claims to be applicable to the terrain in its entirety.

4 Valéry only appears in the last version of the text, which was once known as the "Dritte Fassung" but the latest critical edition (Benjamin, 2013) has now established as the "Fünfte Fassung".

5 Some 36 years later, McLuhan was to kill them off entirely: "Both time (as measured visually and segmentally) and space (as uniform, pictorial, and enclosed) disappear in the electronic age of instant information" (McLuhan, 1994, p. 138).

6 Cf. Benjamin, 1968, p. 221.

7 It is, of course, dangerous to reduce such multifaceted thinkers to single words or simple attitudes. For the sake of argument, Valéry's text is here taken at face value although it is quite clearly imbued with a strong sense of irony. Valéry called the museum's accumulation of "wealth" "a burden and a bewilderment" (Valéry, 1960, p. 205) and Bernard Stiegler uses Valéry as his preferred reference for a pessimistic outlook on spirit, as expressed in Valéry, 1964, p. 190: "All these values, rising and falling, constitute the great stock market of human affairs. On that market, mind ['esprit'] is 'weak' - it is nearly always falling." Cf., e.g., Stiegler, 2011, p. 1. Likewise, Benjamin's hope for technological progress in the Work of Art is nowhere to be found four years later in "Theses on the Philosophy of History" in which "progress" is emphatically derided. And even Heidegger's generally unwavering critique of technology could be overcome by enthusiasm for television as a means for bringing the Gods near, if it showed the masterful football skills of Franz Beckenbauer and his "Mannschaft", cf. Kittler, 2013, p. 390.

8 Cf. Heidegger's critique of modern technology as the challenging of nature in Heidegger, 1977, p. 14.

9 The RFCs (Request for Comments) are a "document series contain[ing] technical and organizational notes about the Internet. They cover many aspects of computer networking, including protocols, procedures, programs, and concepts, as well as meeting notes, opinions, and sometimes humor." http:// www.ietf.org/rfc.html.

10 Cf., e.g., Kittler, 1999, p. 243.

11 Cf. Althusser, 1971, p. 162.

12 Heidegger, 1982, p. 119; cf. also Kittler, 1999, p. 14.

13 Heidegger, 2000, p. 623.

14 Cf. Barthes, 1984.

15 Manoff herself is not such a pundit. On the contrary, she argues for an expansion of the debate concerning the archive.

16 Cf. Derrida, 1995, p. 32; Ernst, 2006, pp. 108-110.

17 Chun, 2008, p. 166.

18 Cf. "computer reading is a writing elsewhere" (Chun, 2011, p. 5).

19 Chun, 2011, p. 25. Cf. also Derrida: "a specter is always a revenant. One cannot control its comings and goings because it begins by coming back" (Derrida, 2006, p. 11).

20 Koyré as cited in Moretti, 2013, p. 113. 
21 "To be sure. The correct always fixes upon something pertinent in whatever is under consideration. However, in order to be correct, this fixing by no means needs to uncover the thing in question in its essence. Only at the point where such an uncovering happens does the true come to pass" (Heidegger, 1977, p. 6).

22 Beniger uses the terms "storage, processing, communication, and control" (Beniger, 1986, p. 32).

23 Cf. Galloway, 2011.

24 Cf., e.g., Galloway, 2008.

25 The following criticism of Latour is limited to his reading of the Heideggerian Thing in Latour, 2004, 2005. A larger discussion of the Latourian framework in general and his specific conceptualization of the digital in particular are, thus, omitted, as are related philosophical stances within Object Oriented Ontology and Speculative Realism. A very important discussion with evidential access to the Thing and the object in Latour and works such as Harman (2002), Bennett (2010), Olsen (2010), Morton (2013), Garcia (2014) and Hansen (forthcoming) requires a separate article, however.

Torsten Arni Caleb Andreasen PhD scholar

Department of Arts and Cultural Studies

University of Copenhagen, Denmark torstenand@hum.ku.dk 